\title{
Does Electronic Monitoring Pay Off?
}

\author{
Influences of Electronic Monitoring Purposes on \\ Organizational Attractiveness
}

\author{
Rudolf Siegel@, Cornelius J. König®, and Leon Porsch \\ Department of Work and Organizational Psychology, Saarland University, Saarbrücken, Germany
}

\begin{abstract}
Applicants often take great care in deciding where to apply and may refrain from applying or accepting a job offer if they hear about privacy-invading practices at a future workplace. Based on communication privacy management theory, the present work examines how applicants react to different purposes of electronic monitoring. In a scenario study, we found higher privacy concerns and lower organizational attractiveness in a situation with controlling monitoring procedures as compared to supportive monitoring procedures. Furthermore, competitive participants evaluated only noncontrolling monitoring procedures more positively. This demonstrates that organizational attractiveness is harmed by controlling monitoring procedures, and decision makers should keep in mind how electronic monitoring is implemented, used, and may be perceived within and outside the organization.
\end{abstract}

Keywords: electronic monitoring, organizational attractiveness, privacy concerns, competitiveness

Today's workplaces are shaped by numerous new technologies that are changing how work is done (e.g., Ghislieri et al., 2018). These changes are highly relevant for employees and may also be noticed by people outside the organization as they might be transported by the media or shared in talks with friends and relatives. Accordingly, such information may potentially affect the image and the attractiveness of the organization in the public realm (Gray \& Balmer, 1998).

Several studies showed that the use of new technologies in the interview setting has an impact on applicant reaction and organization attractiveness (Blacksmith et al., 2016; Langer et al., 2017). What is more, how technology is used at the potential workplace seems to affect people who apply for a similar position as well. In the case of electronic monitoring, Stanton and Lin (2003) found that applicants evaluated an organization as less attractive if they feared privacy invasions through electronic monitoring at the future workplace. However, there are also arguments that despite the invasion of privacy, electronic monitoring can fulfill purposes that might be valued by potential new employees (e.g., Sewell \& Barker, 2006). Thus, it may be possible that the findings of Stanton and Lin (2003) only apply to situations in which potential applicants anticipate that electronic monitoring will be used in a controlling way, thus focusing on the interests of supervisors or the organization rather than the employees.

Therefore, the aim of the current study is to gain further insights into applicants' reactions to electronic monitoring practices that would indicate a privacy invasion at the future workplace. Based on communication privacy management (CPM) theory (Petronio, 1991, 2015) and considering individual differences in applicants' competitiveness, we investigated how engineering students, who are about to apply for jobs, react to different purposes of electronic employee monitoring.

\section{Theory}

\section{Electronic Monitoring of Employees}

Electronic monitoring is a widespread method which is used to obtain, store, and analyze data about employees' performance and behavior at the workplace (Ravid et al., 2019). Research on electronic monitoring has predominantly focused on its effects on employees' well-being mainly finding a negative link (Ravid et al., 2019; Stanton, 2000). Nevertheless, organizations justify electronic monitoring with performance benefits 
and security considerations (Ball, 2010); however, note that there is also research questioning these benefits (Ravid et al., 2019).

Extending previous findings, several authors have highlighted that there is a supportive and controlling aspect of electronic monitoring of employees (DelVecchio et al., 2013; Ravid et al., 2019). Controlling purposes of monitoring are in line with organizational interests such as performance monitoring and policy compliance. In contrast, supportive purposes are aligned with employees' interests such as feedback, rewards, and equal treatment of employees. Whereas the controlling aspect is particularly associated with negative effects on employees' wellbeing, the supportive aspect should promote employees' development (Ravid et al., 2019). Based on CPM theory, we argue that these two kinds of monitoring purposes elicit different responses not only from employees but also from applicants, and we thus introduce CPM theory in the next section.

\section{Communication Privacy Management Theory}

Petronio's (1991, 2015) CPM theory can be used to explain the privacy behavior of individuals and is thus useful in the context of the current study. CPM theory has its origins in describing how information is shared in families and couples (Petronio, 1991) but has successfully applied in research on electronic monitoring (Allen et al., 2007), social media (Frampton \& Child, 2013), and information sharing at the workplace (Smith \& Brunner, 2017). A strength of CPM theory is the possibility to explain decisions that may even harm one's own privacy (Kokolakis, 2017; Petronio, 2015). At its core is a decision-making process which takes benefits and downsides into account and if benefits outweigh the downsides, the outcome of the decision can even harm one's privacy. Compared to other privacy theories, CPM theory is thus particularly suitable for explaining everyday decision outcomes (Kokolakis, 2017). Three key aspects of CPM theory are especially relevant for the current study.

First, CPM theory states that privacy behavior is aimed at fulfilling two conflicting objectives at the same time. On the one hand, people want to retain control of their sensitive information and keep it private. On the other hand, they want to be social and thus need to disclose sensitive information to connect interpersonally and to build a trusting relationship. However, this means that they will lose control over their sensitive information to a certain degree. This contradiction between being open to other individuals and keeping one's autonomy shapes how privacy decisions are made. In the context of the current study, applicants may base their decision on a comparison of benefits (e.g., getting a job) and disadvantages (e.g., revealing information at the later workplace which one does not want to share; see Smith \& Brunner, 2017, as well). Second, CPM proposes that people act according to certain rules which describe how and to whom information is shared. These rules may vary over time and situations. For example, Stanton and Lin (2003) examined whether Black applicants perceive a threat of discrimination in monitoring measures. The authors found that based on the participants' experiences of past situations at the workplace, the described monitoring procedure may elicit different sets of rules (and accordingly, reactions). Finally, different pieces of confidential information have different boundaries, which specify the value of the information; the higher the value, the less likely the information is to be shared. For example, applicants might be willing to share their name or country of origin with a hiring organization but may be less likely to disclose more sensitive information such as their political or sexual orientation.

Thus, CPM theory seems well suited to explain behavior in the context of the current study. In a situation where employees are in a need for a job, they need to balance advantages and disadvantages of a potential future workplace. One key aspect in the current study is the use of electronic monitoring at this future workplace. If participants evaluate a monitoring technique as too intrusive, they probably refrain from applying to an organization and evaluate the organization as less attractive. In terms of CPM theory, the intrusiveness of a monitoring procedure depends on the boundaries employees will assign to certain information and employees' individual privacy rules.

In line with CPM theory and with previous findings on electronic monitoring, we argue that monitoring procedures at a potential workplace have different influences on applicants' reactions depending on whether they are framed as supportive or controlling. Information about the monitoring procedures of a hiring organization might be available from media coverage, social media, and persons who already work at the respective organization. CPM theory suggests that monitoring in a supportive manner might trigger another evaluation of advantages and disadvantages of a potential workplace than monitoring in a controlling manner: Specifically, monitoring in a supportive manner may be seen as more trustful and more in employees' own interest, thus triggering privacy rules that accept information disclosure, whereas applicants may perceive monitoring in a controlling manner to be in the interest of the organization and may believe that it is used for performance and policy observance. If, for 
example, an applicant fears that they may fail to reach performance targets, monitoring can even be detrimental to building a relationship with one's supervisor. Thus, controlling monitoring should provoke a stricter set of privacy rules, and if applicants believe that they cannot maintain their privacy rules, they will probably fear an invasion of their privacy:

Hypothesis 1: Applicants fear less invasion of their privacy when applying to a company with supportive monitoring procedures than in a company with a controlling monitoring procedure.

Organizational attractiveness is a common measure of applicant reactions (Highhouse et al., 2003), and privacy violations are negatively associated with a hiring organization's attractiveness (Ababneh \& Al-Waqfi, 2016). For example, if applicants believe that they cannot maintain their privacy at the future workplace of the hiring organization, they will be less likely to apply for a vacant position or accept a job offer. Thus, we assume that supportive monitoring is associated with higher organizational attractiveness than controlling monitoring:

Hypothesis 2: Applicants evaluate a company with supportive monitoring procedures as more attractive than a company with controlling monitoring procedures.

In addition to supportive and controlling framed monitoring, we wish to examine reactions to a neutral description of the monitoring measures without any framing in either a supportive or controlling way (neutral frame). However, as it is unclear how people react to such a condition in comparison with the two aforementioned conditions, we refrain from proposing a hypothesis for this condition and formulate the following research questions:

Research Question 1: How does monitoring with a neutral framing influence privacy concerns compared to supportive and controlling monitoring procedures?

Research Question 2: How does monitoring with a neutral framing influence organizational attractiveness compared to supportive and controlling monitoring procedures?

\section{Trait Competitiveness}

CPM theory argues that individuals have certain rules by which information is shared as well as certain boundaries that indicate the probability that particular information will be disclosed (Petronio, 1991, 2015). According to
Petronio (2015), these rules and boundaries can be adapted to different situations and altered depending on previous experiences. Although CPM theory does not explicitly address personality traits, it nonetheless includes the argument that people can have differing privacy behavior due to differing privacy rules and thus implicitly incorporates the possibility of individual differences as moderators.

A personality trait that has been shown to play a significant role in the case of electronic monitoring is competitiveness (Gläser et al., 2017). Trait competitiveness is a stable individual characteristic that describes how much people enjoy competing with others (Brown et al., 1998). In addition, competitiveness is positively associated with risk taking (Buser et al., 2014). Thus, in terms of CPM theory, individuals with high competitiveness might take more risk in sharing information to build relationships (e.g., with the supervisor) and may accept or promote the transfer of performance information to other people in the same organization. Thus, we assume overall a negative relationship between competitiveness and privacy invasion. However, different purposes of electronic monitoring might interact with trait competitiveness. Because of higher risk taking of highly competitive peoples, they may see controlling purposes as less intimidating and as a way to show their performance at work. This may lead individuals with high trait competitiveness to perceive control purposes as less threatening than individuals with low competitiveness. Due to the absence of risks, supportive purposes might be accepted independently of one's own competitiveness. Research on the relationship between electronic monitoring and competitiveness is scarce, in particular if monitoring is separated into a controlling and a supporting purpose. Thus, we do not formulate a hypothesis on the interaction of competitiveness with the three framing conditions and instead propose the following research question:

Research Question 3: How does trait competitiveness influence applicant reactions to different framings of electronic monitoring?

\section{Method}

Hypotheses, variables, data collection information, and analyses were registered prior to conducting this study, with the preregistration available at https://aspredicted. org/mp9b7.pdf. In addition, this paper was written as a reproducible manuscript using R (see Aust \& Barth, 2018). All files to reproduce statistical analysis and reports of 
statistics are available at the Open Science Framework (https://osf.io/8vy74/).

\section{Participants}

In the current study, we surveyed 154 engineering undergraduates who were at the end of their bachelor studies and would soon apply for jobs. There is a lack of engineers in the German labor market, and many engineering students have multiple options to work for various organizations (Attström et al., 2014). As such, this sample allows us to examine the effects of monitoring on a sought-after population of undergraduates. Following Meade and Craig (2012), we excluded two participants who stated that they did not respond to the questionnaire seriously. Although we stated in our preregistration that we would exclude participants who failed to pass control questions, several participants stated that one of the two control questions was phrased ambiguously. Accordingly, and given that the results did not substantially differ when including or excluding those participants who failed the control question, we decided to include all remaining participants $(N=152)$. Participants $(18.4 \%$ female) had a mean age of $M=24.34(S D=3.41)$ years. They were in their $M=5.97$ $(S D=2.44)$ semester of a six-semester bachelor's degree course.

\section{Procedure}

Participants were first informed about the procedure and purposes of the study and then completed a paper-andpencil questionnaire. After answering demographic questions, they completed the items regarding competitiveness. In the next step, the scenario was presented. A description of an entry-level job vacancy at a fictitious company called "MobilMaintenance" was given. MobilMaintenance was described as offering services in the aviation industry, namely maintaining private airplanes or as a contractor for firms that are unable to maintain their planes with their existing workforce (see the Appendix for the full scenario).

The description proposed that to become familiar with the maintenance work, job incumbents would wear data glasses that are able to display certain information and to record voice and video so that the maintenance work could be documented. The next part of the description differed depending on the experimental conditions. In the neutral framing condition, it was described that a connection to a supervisor and an experienced mentor is possible. In the controlling framing condition, participants additionally received the following description:

The exact recording of the maintenance work makes it possible to derive data on the work performance and quality of the individual employees. This allows the manager to get an idea of the level of performance of the employees. Through direct communication and the connection to the employee's field of vision, the manager or mentor can detect possible errors directly during maintenance.

Participants in the supportive framing condition instead received the following description:

The accurate recording of maintenance work makes it possible for employees to retrieve data on their work performance and quality. Based on this data, they can get a timely impression of their opportunities for improvement and development. Through the direct communication and the transfer of the field of vision to the manager or the mentor, possible questions can be clarified directly during the maintenance and assistance can be given.

After reading the scenarios, participants were asked to complete the items on organizational attractiveness, privacy concerns, manipulation checks, and faithful responding to the questions. Finally, participants were thanked for their participation. Participants did not receive any compensation for their participation.

\section{Measures}

All responses to the following measures were given on a scale ranging from 1 (strongly agree) to 5 (strongly disagree). For all scales, higher numbers correspond to more agreement on this scale. If a participant had more than two missing values on a scale, the scale mean for this participant was not calculated (a full list of items is available from the supplementary material on the OpenScienceFramework web page).

\section{Competitiveness}

Trait competitiveness was assessed using five items by Brown et al. (1998) in a German version (Gläser et al., 2017). An example item is: "I enjoy working in situations involving competition with others."

\section{Organizational Attractiveness}

We used a German version (Becker et al., 2008) of the Organizational Attractiveness Scale (Highhouse et al., 2003). 
An example items is: "For me, [MobilMaintenance] would be a good place to work." We adapted the questions such that they contained the company name in our scenario instead of "this company." Scale means were calculated across all three subscales: general attractiveness, intentions to pursue, and prestige.

\section{Privacy Concerns}

Privacy concerns were assessed using the 13 items by Alge (2001). An example items is: "I feel personally invaded by the methods used by [MobilMaintenance] to collect personal information." We adapted the questions to contain the company named in our scenario instead of "my organization."

\section{Manipulation Check}

To check manipulation of the scenarios, we asked participants to what degree MobilMaintenance focuses on controlling their employees and on support of their employees. Items were "MobilMaintenance seems to be concerned with developing their employees" and "MobilMaintenance seems to be concerned with controlling their employees." Additionally, two distractor (or filler) items were presented to obscure the purpose of manipulation check items (Kestenbaum \& Hammersla, 1976).

\section{Data Analysis}

Means of the three conditions were analyzed using univariate analysis of variance (ANOVA). Generalized omega squared $\left(\omega_{\text {gen }}^{2}\right)$ is reported as effect size. Differences between individual groups were examined using a Tukey range test.

All analyses were conducted using R (version 3.6.3), and statistical estimates were reported using the easystats ecosystem (Lüdecke et al., 2019). For exploratory purposes, a mediation analysis was conducted using the mediation package (version 4.5.0; Tingley et al., 2014).

\section{Results}

Table 1 presents descriptive statistics of the measured scales.

\section{Manipulation Checks}

Our scenario was presented to the participants in three different conditions: (a) a neutral framing, (b) a controlling framing, and (c) a supportive framing of the monitoring procedures. To check the manipulation of our scenario, we tested whether responses to the item "MobilMaintenance seems to be concerned with employee development" differed between the three conditions. We expected participants in the supportive framing condition to show higher values than participants in the controlling framing condition. We had no specific prior assumptions concerning the neutral framing condition. Using an ANOVA, we found a difference between the three groups, $F(2,148)=3.85$, $p=.024, \omega_{\text {gen }}^{2}=.04,95 \%$ CI $(0.01,0.11)$. Post hoc comparisons revealed a difference between the two experimental conditions, $\Delta M=-0.47,95 \% \mathrm{CI}$ $(-0.89,-0.05), p=.024$. The neutral framing did not differ from the supportive, $\Delta M=-0.36,95 \% \mathrm{CI}$ $(-0.78,0.06), p=.109$, or from the controlling framing, $\Delta M=-0.11,95 \%$ CI $(-0.53,0.31), p=.811$. Thus, participants rated more employee development in the supportive condition than in the controlling condition, and the neutral condition lay between these conditions.

Likewise, we examined differences in the responses to the item "MobilMaintenance seems to be concerned with employee monitoring." Again, we had no specific prior assumptions regarding the neutral framing but expected higher scores in the controlling framing condition than in the supportive framing condition on this item. There was no difference between the three experimental groups, $F(2,149)=2.42, p=.093, \omega_{\text {gen }}^{2}=.02$, $95 \%$ CI $(0.00,0.07)$. By excluding one outlier, the three groups differed, $F(2,149)=3.31, p=.039, \omega_{\text {gen }}^{2}=.03$, $95 \%$ CI $(0.00,0.09)$. This was driven by a difference between the supportive and controlling framing condition, $\Delta M=0.38,95 \% \mathrm{CI}(0.03,0.73), p=.030$, as there was no difference of the neutral condition to the supportive condition, $\Delta M=0.19,95 \%$ CI $(-0.15,0.54)$, $p=.383$, nor to the controlling condition, $\Delta M=0.19,95 \%$ CI $(-0.16,0.53), p=.421$. See Table 2 for scale $M$ (and $S D s)$ of the three conditions.

Table 1. $M, S D$, reliabilities, and correlations

\begin{tabular}{lccccc}
\hline & $M$ & $S D$ & 1 & 2 & 3 \\
\hline 1. Trait competitiveness & 3.37 & 0.68 & $.69^{\mathrm{a}}$ & $.19(.03, .34)$ & $.92^{\mathrm{a}}$ \\
2. Organizational attractiveness & 3.36 & 0.70 & & $-.22(-.37,-.07)$ \\
3. Privacy concerns & 3.19 & 0.72 & &. $.61(-.70,-.50)$ \\
\hline
\end{tabular}

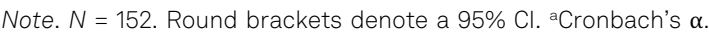


Table 2. $M$ (and SD) of the manipulation check items and dependent variables

\begin{tabular}{lcccc}
\hline & Supportive framing $(n=50)$ & Neutral framing $(n=51)$ & Controlling framing $(n=50)$ & $\omega_{\text {gen }}^{2}(95 \% \mathrm{Cl})$ \\
\hline Manipulation check: development & $3.92(0.92)$ & $3.56(0.88)$ & $3.44(0.86)$ & $.04^{\star}(0.00,0.11)$ \\
Manipulation check: control & $4.06(0.82)$ & $4.25(0.72)$ & $4.38(0.75)$ & $.02(0.00,0.07)$ \\
Competitiveness & $3.39(0.81)$ & $3.40(0.61)$ & $3.34(0.63)$ & $-.01(0.00,0.00)$ \\
Organizational attractiveness & $3.49(0.64)$ & $3.43(0.62)$ & $3.16(0.79)$ & $.03^{*}(0.00,0.10)$ \\
Privacy concerns & $2.98(0.75)$ & $3.17(0.64)$ & $3.42(0.73)$ & $.05^{\star}(0.00,0.12)$ \\
\hline
\end{tabular}

Note. *Indicates a significant group difference $(p<.05)$. Manipulation check: Control is significant if excluding one outlier.

\section{Hypothesis Testing}

Hypothesis 1 stated that participants in the controlling framing condition would express higher privacy concerns than participants in the supportive framing condition. In a first step, we used an omnibus test (ANOVA) to test for differences between the three experimental conditions. The three conditions differed, $F(2,149)=4.76, p=.010$, $\omega_{\text {gen }}^{2}=.05,95 \% \mathrm{CI}(0.00,0.12)$, and post hoc tests indicated a difference between the controlling framing condition and the supportive framing condition, $\Delta M=0.43,95 \% \mathrm{CI}(0.10$, 0.76), $p=.007$. Thus, we found support for Hypothesis 1 . However, the controlling framing condition did not differ from the neutral framing condition, $\Delta M=0.24,95 \%$ CI (0.09, 0.57), $p=.195$. Likewise, the supportive framing condition did not differ from the neutral framing condition, $\Delta M=0.19,95 \%$ CI $(-0.14,0.52), p=.371$. Regarding Research Question 1, the neutral framing condition did not influence privacy concerns in another way than the two experimental conditions. See Table 2 for scale $M$ (and $S D$ s) of the three conditions.

Hypothesis 2, which stated that organizational attractiveness would be higher in the supportive framing condition than in the controlling framing condition, was tested using a similar procedure. An ANOVA yielded differences in organizational attractiveness between the three experimental conditions, $F(2,149)=3.43, p=.035, \omega_{\text {gen }}^{2}=.03,95 \% \mathrm{CI}$ $(0.00,0.10)$. The controlling framing condition differed from the supportive framing condition, $\Delta M=-0.34,95 \% \mathrm{CI}$ $(-0.66,-0.01), p=.040$. Therefore, Hypothesis 2 was supported. Furthermore, we found no difference between the controlling framing condition and the neutral framing condition, $\Delta M=-0.27,95 \%$ CI $(-0.59,-0.05), p=.114$. Likewise, the supportive framing condition did not differ from the neutral framing condition, $\Delta M=-0.06,95 \% \mathrm{CI}$ $(-0.39,-0.26), p=.889$. Thus, the neutral framing condition did not differ in organizational attractiveness from the two experimental conditions (Research Question 2).

\section{Competitiveness}

Figure 1 depicts the interactions with competitiveness. To test the interaction of our three conditions with trait competitiveness, we estimated a regression model predicting privacy concerns with condition and competitiveness and their interaction. To test the interaction effect, we extended the regression analysis by one simple slope analysis (Preacher et al., 2006). In the simple slope analysis, the strength of the relationship (slope) between the independent variable and the dependent variable was calculated for every condition in our study. These slopes can be tested against zero and interpreted. This approach offers a far easier interpretation than a traditional interpretation of an interaction between a continuous variable and a variable with three levels (Preacher et al., 2006). The simple slope analysis yielded a significant relationship between privacy concerns and competitiveness in the neutral framing condition of $b=-0.33,95 \%$ CI $(-0.63,-0.04), t(146)=-2.22$, $p=.028$, and in the supportive framing condition of

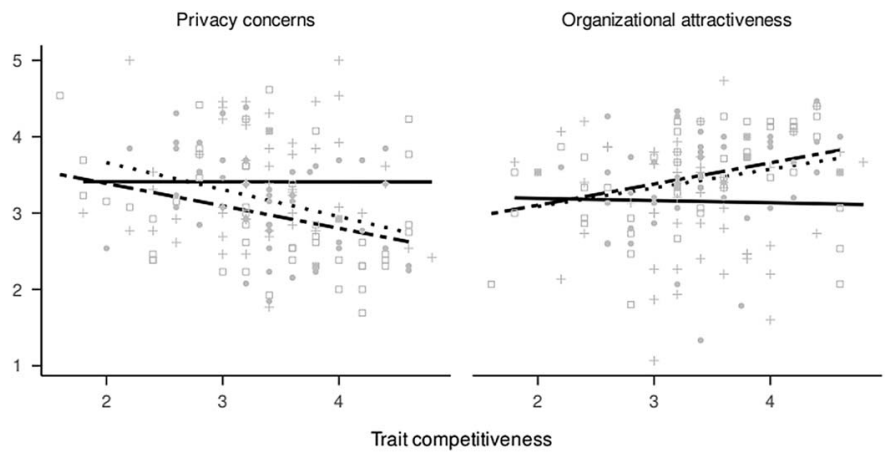

Figure 1. Interaction of privacy concerns and organizational attractiveness with trait competitiveness (regression lines are plotted for each framing condition).

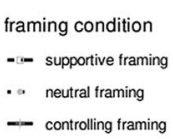


$b=-0.28,95 \%$ CI $(-0.52,-0.03), t(146)=-2.25$, $p=.026$. However, there was no significant relationship in the controlling framing condition, $b=0.00$, $95 \%$ CI $(-0.35,0.35), t(146)=-0.01, p=.994$.

The same analysis was conducted using organizational attractiveness as a dependent variable, revealing a positive relationship between organizational attractiveness and competitiveness in the neutral framing condition of $b=0.24,95 \%$ CI $(0.01,0.47), t(146)=2.05, p=.043$, and in the supportive framing condition of $b=0.27,95 \%$ CI $(0.02,0.53), t(146)=2.10, p=.037$. There was no relationship in the controlling framing condition, $b=-0.03$, $95 \%$ CI $(-0.40,0.34), t(146)=-0.15, p=.879$. To conclude, we found a positive relationship of competitiveness with organizational attractiveness and a negative relationship of competitiveness with privacy concerns in the neutral and supportive framing condition. These relationships did not emerge in the controlling framing condition (Research Question 3).

\section{Exploratory Analyses}

Although not hypothesized prior to the experiment, we conducted a mediation analysis to investigate whether the negative impact of the controlling framing condition on organizational attractiveness was likely mediated by privacy concerns. To ease the interpretation of results, we used only the supportive and controlling framing condition in this analysis. Before introducing the mediated path, the experimental condition was negatively associated with organizational attractiveness, $\beta=-.48,95 \% \mathrm{CI}$ $(-0.89,-0.08), p=.020$, insofar as that participants in the controlling framing condition reported lower organizational attractiveness than those in the supportive framing condition.

After including the mediated path using privacy concerns as the mediator, the direct effect of the condition on organizational attractiveness was no longer significant, $\beta=-.10,95 \%$ CI $(-0.43,0.23), p=.540$, indicating a full mediation. The mediation path showed that the controlling framing condition was positively associated with privacy concerns, $\beta=.60,95 \%$ CI $(0.19,1.00), p=.004$, and privacy concerns were negatively associated with organizational attractiveness, $\beta=-.64,95 \%$ CI $(-0.79,-0.48), p<.001$. A bootstrapped mediation analysis (number of bootstrap samples $=5,000$ ) indicated that the direct path was no longer significant, $-0.10,95 \%$ CI $(-0.41,0.21), p=.514$, whereas there was a significant effect for the indirect path, $0.31,95 \% \mathrm{CI}(0.06,0.58)$, $p=.019$ (total effect: $0.21,95 \%$ CI $(-0.22,0.63), p=.328)$. See Figure 2 for a depiction of the mediation model.

\section{Discussion}

Based on CPM theory (Petronio, 2015), this paper examined the effect of a supportive and a controlling purpose of electronic monitoring at a potential workplace on applicant reactions. We found that applicants evaluate an organization as less attractive if this organization monitors their employees in a controlling manner if the organization monitors their employees in a supporting manner. Similarly, privacy concerns were higher if monitoring is used in a controlling manner compared to a supportive manner. Thus, the current study extended previous findings (Stanton \& Lin, 2003) by revealing that monitoring has different implications for applicant reactions depending on its purpose. With respect to the CPM theory, these findings imply that this theory is not only capable of explaining privacy behavior in interpersonal relationships (Petronio, 2015) and in direct employee-employer relationships (Allen et al., 2007) but can be extended to decisions on a probable future workplace as well. In the current setting, CPM theory implies that different purposes of electronic monitoring change the outcome of comparing benefits and drawbacks of working under electronic control.

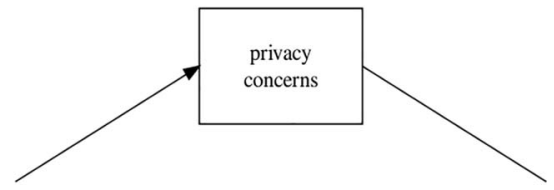

a: $\beta=0.60,95 \% \mathrm{CI}[0.19,1.00]$

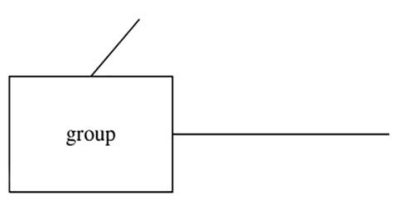

b: $\beta=-0.64,95 \%$ CI $[-0.79,-0.48]$

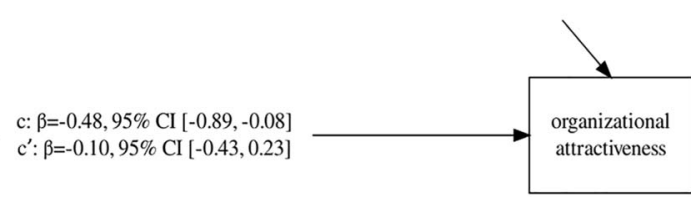

Figure 2. Exploratory mediation model. Paths a and $b$ denote the indirect path, $c$ denotes the direct path before entering the indirect path, and $c$ ' denotes the direct path after entering the indirect path. 
However, the findings of the current study go beyond this. In contrast to the neutral and supportive framing condition, we found no relationship of trait competitiveness with privacy concerns and organizational attractiveness in the controlling framing condition. Thus, highly competitive individuals evaluate monitoring procedures as less threatening, but only if they are noncontrolling and in their interest. In addition, the negative effect of controlling monitoring purposes on organizational attractiveness was fully mediated by privacy concerns. Therefore, privacy concerns or violations that are known to applicants may have a severe impact on the decision to apply for a job and to accept a job offer.

\section{Research and Practical Implications}

Our study has several theoretical and practical implications. First, the current findings support the notion that CPM theory is relevant for recruitment procedures to explain the behavior of applicants in response to monitoring procedures at a potential future workplace. However, we argue that the implications of individual differences warrant further research which could provide the opportunity to clarify how people with certain characteristics shape their privacy rules as well as the permeability of boundaries that define the probability of information sharing. Second, the underlying mechanisms of trait competitiveness and its impact on the reaction to monitoring procedures need to be addressed. In the case of the current study, multiple mechanisms appear to be possible. For example, highly competitive individuals might see monitoring procedures as an opportunity to demonstrate their performance, which would be in line with the definition of competitiveness. However, it is also possible that highly competitive individuals are less intimidated by the social (or remote) presence of their supervisor. Whereas the former explanation places an emphasis on competition per se, the latter focuses on social facilitation (Aiello \& Kolb, 1995; Griffith, 1993).

In the context of electronic monitoring research, the current study has shown that the use and implementation of monitoring procedures does not only affect employees and the organization, but also potential candidates for vacant positions. Ravid et al. (2019) stressed the importance of monitoring purposes and stated that further research is needed in this area. Answering this call for research, the current study showed that not only monitoring procedures are matter for applicants but also their purposes. This emphasizes the relevance of communicating monitoring purposes to employees and ensuring that people understand which data are collected and how they are used.
In addition, the findings of the current study show that decision-makers in organizations should keep in mind how electronic monitoring of their employees is perceived in the public realm. If applicants feel that monitoring procedures at a particular organization would not be in their interest, they may refrain from applying to this organization. This is especially crucial for highly skilled workers (which was the case in our sample) and in times of a shortage of skilled workers (Attström et al., 2014; McDonnell, 2011). Moreover, supervisors should change their leadership style (especially in regard to employee monitoring) in accordance with the competitiveness of their subordinates. Nonetheless, practitioners should keep in mind that electronic monitoring has not only an impact on potential applicants but also on current employees (Ravid et al., 2019). Thus, the actual handling of monitoring and its data is a hint to the prevailing organizational culture and might influence the decision to stay in an organization.

\section{Limitations}

When interpreting the present findings, it should be kept in mind that the study was based on a scenario. Although scenarios are common in electronic monitoring research (e.g., McNall \& Stanton, 2011) and allow experimental research (to test causality), the similarity between applicant behavior in scenarios and in real application situations remains to be tested. In addition, our data stem from a German sample, and applicant behavior may be different in other countries due to different privacy standards and legislation that allow for more (or even less) invasive monitoring procedures (Lasprogata et al., 2004). Thus, in terms of CPM theory, privacy rules and information boundaries may differ in other countries compared to Germany. Beyond that, our scenario was based in the context of a high-reliability organization (Sutcliffe, 2011) where the decision to implement electronic monitoring might be seen as more acceptable than in non-high-reliability-organizations. Nevertheless, it should be noted that our results regarding controlling monitoring are comparable to the findings reported by Stanton and Lin (2003) in the United States and a nonhigh-reliability-organizations context, suggesting that our findings should also hold for other countries and situations.

Finally, we would like to point at issues with our manipulation check based on the discussion in Hauser et al. (2018). Like other scales and items, manipulation checks have a certain measurement error (in terms of classical test theory; Novick, 1966). Our manipulation check consists of only two items; thus, it is probably quite strongly affected 
by measurement error. Another issue is the order of presentation of manipulation checks and dependent variables. Our manipulation checks were presented after measuring the dependent variables. This has the advantage that the dependent variables are unaffected by any reactions that our manipulation checks might provoke but is overly conservative because of the late presentation (Hauser et al., 2018).

Based on the limitations and findings of the current study, we argue that electronic monitoring at the workplace has implications on an organizations' attractiveness for applicants. Further research is warranted to get better insights into effects of the current findings on real-world applicants. For example, subsequent studies could estimate how severe effects are for organizations that are well known to implement invasive monitoring techniques (like Amazon; Cattero \& D’Onofrio, 2018). Different samples (like professions that are understaffed or not) and organization types could be considered. In addition, further research is needed to clarify the underlying mechanisms of competitiveness on applicant reactions.

\section{References}

Ababneh, K. I., \& Al-Waqfi, M. A. (2016). The role of privacy invasion and fairness in understanding job applicant reactions to potentially inappropriate/discriminatory interview questions. Personnel Review, 45(2), 392-418. https://doi.org/10.1108/PR11-2014-0264

Aiello, J. R., \& Kolb, K. J. (1995). Electronic performance monitoring and social context: Impact on productivity and stress. Journal of Applied Psychology, 80(3), 339-353. https://doi.org/10.1037/ 0021-9010.80.3.339

Alge, B. J. (2001). Effects of computer surveillance on perceptions of privacy and procedural justice. Journal of Applied Psychology, 86(4), 797-804. https://doi.org/10.1037/0021-9010.86.4.797

Allen, M. W., Coopman, S. J., Hart, J. L., \& Walker, K. L. (2007). Workplace surveillance and managing privacy boundaries. Management Communication Quarterly, 21(2), 172-200. https:// doi.org/10.1177/0893318907306033

Attström, K., Niedlich, S., Sandvliet, K., Kuhn, H.-M., \& Beavor, E. (2014). Mapping and analysing bottleneck vacancies in EU labour markets. European Commission. https://ec.europa.eu/eures/ downloadSectionFile.do?fileld $=8010$

Aust, F., \& Barth, M. (2018). papaja: Create APA manuscripts with $R$ Markdown. https://github.com/crsh/papaja

Ball, K. (2010). Workplace surveillance: An overview. Labor History, 51(1), 87-106. https://doi.org/10.1080/00236561003654776

Becker, W., Fischer, S., Staffel, M., \& Ulrich, P. (2008). Einflussfaktoren auf das Bewerberverhalten von Studierenden: Ergebnisbericht einer experimentellen Untersuchung [Factors influencing the application behavior of undergraduates: Report of an experimental survey]. http://www.uni-bamberg.de/fileadmin/uni/fakultaeten/sowi_ lehrstuehle/unternehmensfuehrung/Download-Bereich/BBB_ 148_Experiment_CFA_ungeschuetzt.pdf
Blacksmith, N., Willford, J., \& Behrend, T. (2016). Technology in the employment interview: A meta-analysis and future research agenda. Personnel Assessment and Decisions, 2(1), 12-20. https://doi.org/10.25035/pad.2016.002

Brown, S. P., Cron, W. L., \& Slocum, J. W. (1998). Effects of trait competitiveness and perceived intraorganizational competition on salesperson goal setting and performance. Journal of Marketing, 62(4), 88-98. https://doi.org/10.2307/1252289

Buser, T., Niederle, M., \& Oosterbeek, H. (2014). Gender, competitiveness, and career choices. Quarterly Journal of Economics, 129(3), 1409-1447. https://doi.org/10.1093/qje/qju009

Cattero, B., \& D'Onofrio, M. (2018). Organizing and collective bargaining in the digitized "tertiary factories" of Amazon: A comparison between Germany and Italy. In E. Ales, Y. Curzi, T. Fabbri, O. Rymkevich, I. Senatori, \& G. Solinas (Eds.), Working in digital and smart organizations (pp. 141-164). Palgrave Macmillan. https://doi.org/10.1007/978-3-319-77329-2_8

DelVecchio, S. K., Deeter-Schmelz, D. R., \& Anselmi, K. (2013). Big Brother or big bother? E-monitoring the salesforce. Journal of Business \& Industrial Marketing, 28(4), 288-302. https://doi.org/ $10.1108 / 08858621311313893$

Frampton, B. D., \& Child, J. T. (2013). Friend or not to friend: Coworker Facebook friend requests as an application of communication privacy management theory. Computers in Human Behavior, 29(6), 2257-2264. https://doi.org/10.1016/j.chb.2013. 05.006

Ghislieri, C., Molino, M., \& Cortese, C. G. (2018). Work and organizational psychology looks at the fourth industrial revolution: How to support workers and organizations? Frontiers in Psychology, 9, 2365. https://doi.org/10.3389/fpsyg.2018.02365

Gläser, D., van Gils, S., \& Van Quaquebeke, N. (2017). Pay-forperformance and interpersonal deviance. Journal of Personnel Psychology, 16(2), 77-90. https://doi.org/10.1027/1866-5888/ a000181

Gray, E. R., \& Balmer, J. M. T. (1998). Managing corporate image and corporate reputation. Long Range Planning, 31(5), 695-702. https://doi.org/10.1016/S0024-6301(98)00074-0

Griffith, T. L. (1993). Monitoring and performance: A comparison of computer and supervisor monitoring. Journal of Applied Social Psychology, 23(7), 549-572. https://doi.org/10.1111/j.1559-1816. 1993.tb01103.x

Hauser, D. J., Ellsworth, P. C., \& Gonzalez, R. (2018). Are manipulation checks necessary? Frontiers in Psychology, 9, 998. https://doi.org/10.3389/fpsyg.2018.00998

Highhouse, S., Lievens, F., \& Sinar, E. F. (2003). Measuring attraction to organizations. Educational and Psychological Measurement, 63(6), 986-1001. https://doi.org/10.1177/0013164403258403

Kestenbaum, J. M., \& Hammersla, J. (1976). Filler items and social desirability in Rotter's locus of control scale. Journal of Personality Assessment, 40(2), 162-168. https://doi.org/10.1207/ s15327752jpa4002_7

Kokolakis, S. (2017). Privacy attitudes and privacy behaviour: A review of current research on the privacy paradox phenomenon. Computers \& Security, 64, 122-134. https://doi.org/10.1016/j. cose.2015.07.002

Langer, M., König, C. J., \& Krause, K. (2017). Examining digital interviews for personnel selection: Applicant reactions and interviewer ratings. International Journal of Selection and Assessment, 25(4), 371-382. https://doi.org/10.1111/ijsa.12191

Lasprogata, G., King, N. J., \& Pillay, S. (2004). Regulation of electronic employee monitoring: Identifying fundamental principles of employee privacy through a comparative study of data privacy legislation in the European Union, United States and Canada. Stanford Technology Law Review, 2004, 4-77.

Lüdecke, D., Waggoner, P., \& Makowski, D. (2019). insight: A unified interface to access information from model objects in R. Journal 
of Open Source Software, 4(38), 1412. https://doi.org/10.21105/ joss.01412

McDonnell, A. (2011). Still fighting the "war for talent"? Bridging the science versus practice gap. Journal of Business and Psychology, 26(2), 169-173. https://doi.org/10.1007/s10869-011-9220-y

McNall, L. A., \& Stanton, J. M. (2011). Private eyes are watching you: Reactions to location sensing technologies. Journal of Business and Psychology, 26(3), 299-309. https://doi.org/10. 1007/s10869-010-9189-y

Meade, A. W., \& Craig, S. B. (2012). Identifying careless responses in survey data. Psychological Methods, 17(3), 437-455. https://doi. org/10.1037/a0028085

Novick, M. R. (1966). The axioms and principal results of classical test theory. Journal of Mathematical Psychology, 3(1), 1-18. https://doi.org/10.1016/0022-2496(66)90002-2

Petronio, S. (1991). Communication boundary management: A theoretical model of managing disclosure of private information between marital couples. Communication Theory, 1(4), 311-335. https://doi.org/10.1111/j.1468-2885.1991.tb00023.x

Petronio, S. (2015). Communication privacy management theory. In C. R. Berger, M. E. Roloff, S. R. Wilson, J. P. Dillard, J. Caughlin, \& D. Solomon (Eds.), The international encyclopedia of interpersonal communication (pp. 1-9). Wiley.

Preacher, K. J., Curran, P. J., \& Bauer, D. J. (2006). Computational tools for probing interactions in multiple linear regression, multilevel modeling, and latent curve analysis. Journal of Educational and Behavioral Statistics, 31(4), 437-448. https://doi. org/10.3102/10769986031004437

Ravid, D. M., Tomczak, D. L., White, J. C., \& Behrend, T. S. (2019). EPM 20/20: A review, framework, and research agenda for electronic performance monitoring. Journal of Management, 46(1), 100-126. https://doi.org/10.1177/0149206319869435

Sewell, G., \& Barker, J. R. (2006). Coercion versus care: Using irony to make sense of organizational surveillance. Academy of Management Review, 31(4), 934-961. https://doi.org/10.5465/ amr.2006.22527466

Smith, S. A., \& Brunner, S. R. (2017). To reveal or conceal: Using communication privacy management theory to understand disclosures in the workplace. Management Communication Quarterly, 31(3), 429-446. https://doi.org/10.1177/0893318917692896

Stanton, J. M. (2000). Reactions to employee performance monitoring: Framework, review, and research directions. Human Performance, 13(1), 85-113. https://doi.org/10.1207/S15327043HUP1301_4

Stanton, J. M., \& Lin, L. F. (2003). Effects of workplace monitoring policies on potential employment discrimination and organizational attractiveness for African Americans in the technical professions. Journal of Black Psychology, 29(3), 257-274. https://doi.org/10.1177/0095798403254210

Sutcliffe, K. M. (2011). High reliability organizations (HROs). Best Practice \& Research Clinical Anaesthesiology, 25(2), 133-144. https://doi.org/10.1016/j.bpa.2011.03.001

Tingley, D., Yamamoto, T., Hirose, K., Keele, L., \& Imai, K. (2014). mediation: R package for causal mediation analysis. Journal of Statistical Software, 59(1), 1-38. https://doi.org/10.18637/jss.v059.i05

\section{History}

Received September 28, 2020

Revision received January 20, 2021

Accepted January 21, 2021

Published online June 1, 2021

\section{Funding}

This research was supported by the Kooperationsstelle für Wissenschaft und Arbeitswelt (KoWA) and Arbeitskammer Saarland (Project: "Auswirkungen des elektronischen Überwacht-Werdens auf Arbeitnehmerinnen und Arbeitnehmer" [The impact of electronic monitoring on employees]). Open access publication enabled by Saarland University and State Library.

\section{Open Data}

Preregistered files are available at https://aspredicted.org/ mp9b7.pdf. All files to reproduce statistical analysis and reports of statistics are available at the Open Science Framework at https://osf.io/8vy74/.

\section{ORCID}

Rudolf Siegel

(D) https://orcid.org/0000-0002-6021-804X

Cornelius J. König

(iD) https://orcid.org/0000-0003-0477-8293

\section{Rudolf Siegel}

Department of Work and Organizational Psychology

Saarland University

Campus A1.3

66123 Saarbrücken

Germany

rudolf.siegel@uni-saarland.de

\section{Appendix}

\section{Complete Scenarios}

The following description was provided to all participants:

The company MobilMaintenance is offering several positions for young professionals in the engineering sector. You are thinking about applying for one of the positions. The company offers services in the field of aviation maintenance. The company is often contracted, for example, when an airline cannot guarantee punctual and reliable maintenance due to a lack of personnel at an airport or when a private jet of a company needs maintenance.

The requirements of the job advertised are to control and optimize maintenance procedures. In order to gain experience in maintenance procedures, an induction training course is held prior to the job, in which entry-level employees work together with experienced persons to carry out maintenance on aircraft. A former fellow student of yours has already been working at MobilMaintenance for 1 year. After seeing the job advertisement, you meet with him to get more information about the company and the job. According to his report, MobilMaintenance seems to have a fairly modern approach.

During certain maintenance operations, all employees wear digital glasses that are connected to their work cell phones. The device can display information in the field of vision and contains both a camera and a microphone. This makes it possible to display maintenance plans 
quickly and easily and to record maintenance work by photo and voice recording. In addition, the camera of the digital glasses can also transmit the employee's field of vision, thus enabling direct video telephony with the manager or an experienced mentor.

In the controlling framing condition, participants additionally received the following description:

The exact recording of the maintenance work makes it possible to derive data on the work performance and quality of the individual employees. This allows the manager to get an idea of the level of performance of the employees. Through direct communication and the connection to the employee's field of vision, the manager or mentor can detect possible errors directly during maintenance.
Participants in the supportive framing condition instead received the following description:

The accurate recording of maintenance work makes it possible for employees to retrieve data on their work performance and quality. Based on this data, they can get a timely impression of their opportunities for improvement and development. Through the direct communication and the transfer of the field of vision to the manager or the mentor, possible questions can be clarified directly during the maintenance and assistance can be given.

Finally, all participants read the following sentence:

On the way home, you try to classify the newly acquired information about MobilMaintenance. 